\title{
Lectin-Binding Glycoconjugates in the Subfornical Organ of the Rat
}

\author{
By
}

\author{
Takashi UEDA, Osamu FUJIMORI and Kazuyori YAMADA \\ 2nd Department of Anatomy, Nagoya City University Medical School, \\ 1 Kawasumi, Mizuho-cho, Mizuho-ku, Nagoya 467, Japan
}

- Received for Publication, January 31, 1977 -

Key Words: Lectins, Glycoconjugates, Histochemistry, Rat, Subfornical Organ

\begin{abstract}
Summary: In the rat subfornical organ (SFO), lectin-binding glycoconjugates were histochemically examined by 9 biotinylated lectins using a streptavidin-biotin peroxidase system. The strong or moderate bindings of Canavalia ensiformis (Con A), Lens culinaris (LCA) and Phaseolus vulgaris erythroagglutinin (ePHA) indicated overall distributions of high mannose, intermediate, hybrid $\mathrm{N}$-linked, and non-bisected and bisected, bi/triantennate $\mathrm{N}$-linked complex oligosaccharides in the rat SFO. Nonsialylated terminal N-acetylglucosamines were detected throughout this organ, as revealed by its stainabilities with Triticum vulgaris (WGA) and Limax flavus (LFA). In this organ, Ricinus communis (RCA-1) specifically bound to vessel-associated structures, whereas Arachis hypogaea (PNA) reacted with selected neurons in the central and rostral regions of this organ. Dolichos biflorus (DBA) and Ulex europaeus (UEA-1) did not stain any histologic structures in the rat SFO. The results obtained in this study provide a basis for comprehensive analyses of glycoconjugates in the rat SFO.
\end{abstract}

The subfornical organ (SFO) is known to be one of the circumventricular organs located in the third ventricle between the interventricular foramina of the lateral ventricles (Fig. 1) (Hofer, 1959). It is characterized by the absence of blood-brain barrier capable of receiving blood-borne substances, such as angiotensin II (Sirett $e t$ al., 1977), atrial natriuretic factor (ANF) (Quirion et al., 1984), steroid hormone (Stumpf et al., 1992) and somatostatin (Krisch, 1992). In the rat, the SFO has been subdivided into three (rostral, central and caudal) regions (Fig. 2) (Dellman and Simpson, 1976). The rostral and caudal regions are dominated by nerve projections interspersed with a few neurons and glial cells, whereas the central region contains most of the neuronal perikarya, glial cells and highly developed vessel systems. This organ has been reported to participate in the control of body fluid balance and in the neuroendocrine functions (Miselis et al., 1979; Summy-Long and Severs, 1979; Lepetit et al., 1992), however, its exact functions still remain to be elucidated.

Lectins are proteins or glycoproteins of non-immune natures, which bind to specific sugar residues, sugar linkage, or oligomers in glycoconjugates. They have been introduced into the histochemistry of carbohydrates and have widely been used as valuable probes for the specific detection of oligosaccharide moieties in glycoconjugates (Spicer and Schulte, 1992). In mammalian neural tissues, glycoconjugates have been postulated to play a role in a number of important physiological activities, such as cell to cell interactions, myelination, synapse formation, impulse conduction and storage and release of hormones and biogenic amines (Margolis and Margolis, 1979). Despite these, however, only few attempts have so far been made to histochemically study glycoconjugates contained in the SFO.

The aim of the present study was to demonstrate the localizations and histochemical properties of specific sugar residues of glycoconjugates in the SFO of the rat by means of techniques of light microscopic lectin histochemistry.

\section{Materials and Methods}

\section{Lectins}

The following biotinylated lectins were obtained from Honen Corporation (Tokyo, Japan); Canavalia ensiformis (Con A), Phaseolus vulgaris erythroagglutinin (ePHA), Lens culinaris (LCA), Triticum vulgaris (WGA), Ricinus communis (RCA-1), Arachis 
hypogaea (PNA), Dolichos biflorus (DBA) and Ulex europaeus (UEA-1). Biotinylated Limax flavus (LFA) lectin was purchased from EY Laboratories (CA, USA) (Table 1).

\section{Tissue preparations}

Brains were dissected out from 6 adult male SpragueDawley rats weighing 250-330 g (8-10 weeks of ages) following the sacrifice of the donor animals by decapitation under Nembtal anaesthesia. The entire brain from each rat was immediately sliced on sagittal planes at a thickness of $5 \mathrm{~mm}$ and then slices containing the SFO were fixed in Bouin's fluid for 6 hours at room temperature. Following fixation, the fixed tissues were washed and dehydrated in $100 \%$ ethanol series, cleared in xylene and embedded in paraffin wax. Sections were cut at $5 \mu \mathrm{m}$ in thickness and mounted on glass slides without any adhesives. Tissue sections were then dewaxed with xylene, hydrated in an ethanol series of descending concentrations and subjected to the lectin histochemical methods as described below. The stained sections were dehydrated in a graded ethanol series, cleared in xylene and mounted in Harleco synthetic resin (HSR) (Kokusai Shiyaku, Kobe, Japan).

\section{Lectin histochemistry}

Dewaxed and hydrated tissue sections were immersed in $0.3 \% \mathrm{H}_{2} \mathrm{O}_{2}$ in methanol for $30 \mathrm{~min}$ to suppress the activity of endogenous peroxidase, rinsed in phosphate buffer saline (0.01 M, pH 7.4) (PBS), treated with $0.5 \%$ bovine serum albumin (BSA; Sigma Chemical Co., St. Louis, Mo, USA)-PBS for $15 \mathrm{~min}$ and reacted with a biotinylated lectin (Table 1) solution diluted 1:40 with BSA-PBS at room temperature for $1 \mathrm{~h}$. The slides were then rinsed in PBS, incubated with streptavidin-horseradish peroxidase (Seikagaku Corp., Tokyo, Japan) at room temperature for $10 \mathrm{~min}$, rinsed in PBS and incubated in diaminobenzidine (DAB) (Katayama Chemical Co., Osaka, Japan)- $\mathrm{H}_{2} \mathrm{O}_{2}$ medium (DAB $30 \mathrm{mg}$, $30 \% \mathrm{H}_{2} \mathrm{O}_{2} 26 \mu \mathrm{l}, 0.05 \mathrm{M}$ Tris $\mathrm{HCl}$ buffer $\left.150 \mathrm{ml}\right)(\mathrm{pH}$ 7.6) at room temperature for $15 \mathrm{~min}$. The specificities of lectin binding reactions were substantiated by incubation of control tissue sections in lectin solutions containing respective inhibitory sugars (Table 1).

\section{Results}

In the present study, the histochemical reactions obtained were evaluated in terms of the three regions of the SFO (Fig. 2), as described in the "Introduction".

\section{Con A}

In the SFO, the lectin Con A (Fig. 3) uniformly bound to all the histologic structures in the three regions, including neuronal perikarya, their dendrites and axons, afferent and efferent nerve projections, glial cells, ependyma, vascular walls, and perivascular spaces. The

Table 1. Biotinylated lectins used in the present study

\begin{tabular}{|c|c|c|c|}
\hline origins & abbreviations & specificities & inhibitory sugars \\
\hline Canavalia ensiformis & Con A & $\begin{array}{l}\alpha \text {-D-glucosyl and } \alpha \text {-D-mannosyl residues in high } \\
\text { mannose, intermediate and small complex } N \text {-linked } \\
\text { sequences }\end{array}$ & $\begin{array}{l}0.2 \mathrm{M} \alpha \text {-methyl-D- } \\
\text { mannoside }\end{array}$ \\
\hline $\begin{array}{l}\text { Phaseolus vulgaris } \\
\text { erythroagglutinin }\end{array}$ & ePHA & $\begin{array}{l}\text { Bisected bi- and triantennate complex } \mathrm{N} \text {-linked } \\
\text { sequences }\end{array}$ & None \\
\hline Lens culinaris & LCA & $\begin{array}{l}\alpha-D-m a n n o s e \text { in non-bisected bi- and triantennate, } \\
\text { complex } N \text {-linked sequences }\end{array}$ & $\begin{array}{l}0.2 \mathrm{M} \alpha \text {-methyl-D- } \\
\text { mannoside }\end{array}$ \\
\hline Triticum vulgaris & WGA & $\begin{array}{l}\text { Di-N-acetyl chitobiosyl, } \mathrm{N} \text {-acetyllactosaminyl and } \\
\text { some sialyl residues }\end{array}$ & $\begin{array}{l}0.1 \mathrm{M} \text { di-N-acetyl } \\
\text { chitobiose }\end{array}$ \\
\hline Ricinus communis & RCA-1 & $\begin{array}{l}\text { Galactosyl } \beta 1,4 \mathrm{~N} \text {-acetylglucosaminyl sequences }> \\
\beta \text {-galactosyl terminals }>\alpha \text {-galactosyl terminals }\end{array}$ & $0.1 \mathrm{M} \mathrm{D}$-galactose \\
\hline Arachis hypogaea & PNA & $\begin{array}{l}\text { Galactosyl } \beta 1,3 \mathrm{~N} \text {-acetylgalactosaminyl }>\mathrm{N} \text {-acetyl- } \\
\text { lactosaminyl sequences }\end{array}$ & $0.1 \mathrm{M} \mathrm{D}$-galactose \\
\hline Dolichos biflorus & DBA & $\alpha-\mathrm{N}$-acetylgalactosaminyl terminals & $\begin{array}{l}0.1 \mathrm{M} \mathrm{N} \text {-acetyl- } \\
\text { galactosamine }\end{array}$ \\
\hline Ulex europaeus & UEA-1 & $\alpha$-L-fucosyl terminals & $0.1 \mathrm{M} \alpha$-L-fucose \\
\hline Limax flavus & LFA & Certain sialyl terminals & None \\
\hline
\end{tabular}


neuronal perikarya and ependyma were stained more vividly, as compared with the rest of Con A reactive histologic structures.

\section{ePHA}

ePHA (Fig. 4) bound in various intensities to the same histologic structures as those exhibiting positive Con A reactions. In the neuronal perikarya, however, this lectin did not react so markedly as Con A.

\section{$L C A$}

LCA (Fig. 5) bound to neuronal and glial networks in all the regions of the SFO. The neuronal perikarya and ependymal cells were stained more strongly. The blood vessels contained in all the regions did not exhibit any strong reactions with this lectin (Fig. 5).

\section{$W G A$}

WGA (Fig. 6) moderately stained all the histologic structures in the SFO, however, some neuronal and glial cells and ependymal cells exhibited strong positive reactions.

\section{RCA-1}

Characteristically, RCA-1 (Figs. 7,8) stained vividly vessel-associated structures, certain neuronal and glial cells and ependymal cells throughout this organ. In particular, such positive reactions were widely distributed in the central and caudal regions. This lectin did not bind to other histologic structures than those mentioned at all.

\section{PNA}

The lectin PNA (Figs. 9, 10) strongly bound to selective neuronal perikarya, their dendrites and axons, nerve projections in both the central and rostral regions of the SFO.

\section{$L F A$}

The lectin LFA (Fig. 11) exhibited doubtful reactions throughout the organ, whereas the epithelial cells of the choroid plexus were stained moderately by this lectin.

\section{$D B A, U E A-1$}

Both the lectins DBA (Fig. 12) and UEA-1 (Fig. 13) did not stain any histologic structures in this organ, whereas ventral hippocampal commissure in contact with the SFO exhibited moderate positive reactions.

\section{Controls}

If each lectin was pre-absorbed with the appropriate inhibitory sugars, any positive reactions was not obtained throughout all the histologic structures composing the SFO (Fig. 14).

\section{Discussion}

In light microscopic histochemistry of glycoconjugates using paraffin sections, lectins are generally known to visualize oligosaccharides of glycoproteins, but not glycosaminoglycans with a possible exception of keratan sulfate (Spicer and Schulte, 1992).

Con A, LCA and ePHA have been used to identify various classes of $\mathrm{N}$-linked oligosaccharides (Table 1) (McMahon et al., 1989). Thus, the strong or moderate positive reactions of Con A,LCA and ePHA throughout the rat $S F O$ suggest that high mannose, intermediate and hybrid N-linked, and non-bisected and bisected, bi/ triantennate complex $\mathrm{N}$-linked oligosaccharides are widely distributed in the rat SFO. WGA specifically reacts with $\mathrm{N}$-acetylglucosamine and certain sialic acid residues (Debray et al., 1981) and incidentally binds to keratan sulfates (Toda et al., 1981). In contrast, LFA exhibits a specificity exclusively towards sialic acid residues (Miller et al., 1982). Therefore, the strong or moderate stainings with WGA and doubtful reaction with LFA are taken to suggest the presence of glycoconjugates with $\mathrm{N}$-acetylglucosamine but without sialic acids in this organ. RCA-1 binds to galactose $(\beta 1,4) \mathrm{N}$-acetylglucosamine and terminal galactose (Debray et al., 1981). PNA reacts not only with terminal galactose $(\beta 1,3) \mathrm{N}$-acetylgalactosamine but with galactose $(\beta 1,4) \mathrm{N}$-acetylglucosamine (Lotan and Sharon, 1978). In the rat SFO, therefore, oligosaccharides with galactose $(\beta 1,4) \mathrm{N}$-acetylglucosamine and/or terminal galactose are localized in the vessel-associated structures, certain neuronal and glial cells and ependymal cells, whereas those with terminal galactose $(\beta 1,3) \mathrm{N}$ acetylgalactosamine are contained in the selected neurons of the central and rostral regions of this organ. DBA exhibits a specificity towards terminal $\mathrm{N}$ acetylgalactosamine of $\mathrm{O}$-glycosidically linked oligosaccharides (Baker et al., 1983). UEA-1 specifically reacts with $\alpha$-Fucose at a branch or terminal position of oligosaccharides (Alroy et al., 1988). In the SFO, oligosaccharides with such carbohydrate moieties were devoid of any histologic structures involved.

In mammalian nervous system, certain lectins have been shown to interact with both neuronal and glial cells. For instance, Con A and RCA were reported to bind to post-synaptic densities of isolated cortical synaptic membrane (Gurd, 1977). Further, PNA stained most small neurons in sensory ganglia and myelinated fibers in the white matter of the spinal cord (Streit et al., 1985), whereas Vicia villosa lectin with a specificity for terminal $\mathrm{N}$-acetylgalactosamine reacted with most GABAergic neurons in the thalamic reticular nucleus of rodent brains (Nakagawa et al., 1986). In neuroglia, RCA-1 and Griffonia simplicifolia lectin have been presumed as a microglial cell marker (Mannoji et al., 1986; Boya et al., 1991). In addition, receptors with 
different functions have been reported to show affinity towards various lectins in mammalian nervous system. Nicotinic acetylcholine receptors from rat brain exhibited affinities towards Con A, WGA and RCA (Salvaterra et al., 1977). Glutamate binding proteins containing synaptic membrane (Michaelis, 1975) and opiate receptors (Gioannini et al., 1982) were visualized by Con A and WGA respectively. Since the SFO has been recorded to consist of neurons and glia with a variety of receptors for neurotransmitters and circulating substances (Sirett et al., 1977; Quirion et al., 1984, Palkovits et al., 1992; Weindl et al., 1992), the present lectin staining reactions could perhaps be correlated with the structures and functions of these receptors. In mammalian SFO, the rostral region has been reported to consist of functionally important fibers containing output pathways concerned with the maintenance of body fluid and cardiovascular homeostasis (Sposito and Gross, 1987; Johnson et al., 1992). In the rat SFO, therefore, the PNAreactive glycoconjugates localized in this region could possibly be correlated with the transmission of informations received.

The results obtained in the present study are believed to be useful informations for the elucidation of the true physiological functions of the rat SFO. However, further critical studies with electron microscopic lectin histochemistry may be needed for a thorough understanding of the true physiological activities of the mammalian SFO.

\section{Acknowledgements}

The authors wish to express their thanks to Mr. K. Kajita for his technical assistances.

\section{References}

1) Alroy J, Ucci AA and Periera ME. Lectin histochemistry. In "Advances in Immunohistochemistry", ed. by R. A. Delellis, 93-131, Raven Press, New York, 1988.

2) Baker DA, Kabat SS, Ratcliffe RM, Hermentin $P$ and Lemieux RU. Immunochemical studies on the combining sites of Forssman hapten reactive hemagglutinins from Dolichos biflorus, Helix pomata, and Wistaria floribunda. Biochemistry 1983;22:27412750.

3) Boya J, Carbonell AL, Calvo JL and Borregon A. Microglial cells in the central nervous system of the rabbit and rat: cytochemical identification using two different lectins. Acta Anat 1991; 140:250-253.

4) Debray H, Decout D, Strecker G, Spik D and Montreuil J. Specificity of twelve lectins towards oligosaccharides and glycopeptides related to $\mathrm{N}$-glycosylproteins. Eur J Biochem 1981; 117:41-55.

5) Dellman H-D and Simpson JB. Regional differences in the morphology of the rat subfornical organ. Brain Res 1976; 116:389-400.

6) Gioannini T, Foucaud B, Hiller JM, Hatten ME and Simon EJ.
Lectin binding of solubilized opiate receptors: Evidence for their glycoprotein nature. Biochem Biophys Res Commun 1982; 105:1128-1134.

7) Gurd JW. Identification of lectin receptors associated with rat brain postsynaptic densities. Brain Res 1977; 126:154-159.

8) Hofer H.Zur Morphologie der circumventrikulären Organe des Zwischenhirns der Säugetiere. Verh. Dtsch. Zool. Ges. Frankfurt a. M. 1958. Zool Anz 1959; 22:202-251.

9) Johnson AK, Zardetto-Smith AM and Edwards GL. Integrative mechanisms and the maintenance of cardiovascular and body fluid homeostasis: the central processing of sensory input derived from the circumventricular organs of the lamina terminalis. Prog Brain Res 1992; 91:381-393.

10) Krisch B. Somatostatin-binding sites on the structures of circumventricular organs. Prog Brain Res 1992; 91:247-250.

11) Lepetit P, Grange E, Gay N and Bobillier P. Progressive increases of protein synthesis in the circumventricular organs during chronic dehydration in rats. Prog Brain Res 1992; 91:435-438.

12) Lotan R and Sharon N. Peanut Arachis hypogaea agglutinin. Meth Enzymol 1978; 50:361-367.

13) Mannoji $\mathrm{H}$, Yeger $\mathrm{H}$ and Becker LE. A specific histochemical marker (lectin Ricinus communis agglutinin-1) for normal human microglia, and application to routine histopathology. Acta Neuropathol 1986; 71:341-343.

14) Margolis RK and Margolis RU. Structure and distribution of glycoproteins and glycosaminoglycans. In "Complex Carbohydrates of Nervous Tissue", ed. by R. U. Margolis and R. K. Margolis, 45-73, Plenum Press, New York, 1979.

15) McMahon RFT, Benbow EW, Lofthouse AK and Stoddart RW Human salivary gland glycoconjugates: a lectin histochemical study. Histochem J 1989; 21:663-674.

16) Michaelis EK. Partial purification and characterization of a glutamate-binding membrane glycoprotein from rat brain Biochem Biophys Res Commun 1975; 65:1004-1012.

17) Miller RL, Collawn JF Jr. and Fish WW. Purification and macromolecular properties of a sialic acid-specific lectin from the slug Limax flavus. J Biol Chem 1982; 257:7574-7580.

18) Miselis RR, Shapiro RE and Hand PJ.Subfornical organ efferents to neural systems for control of body water. Science 1979; 205:1022-1025.

19) Nakagawa F, Schulte BA, Wu J-Y and Spicer SS. GABAergic neurons of rodent brain correspond partially with those staining for glycoconjugate with terminal $\mathrm{N}$-acetylgalactosamine. J Neurocytol 1986; 15:389-396.

20) Palkovits M, Bahner U, Geiger H, Fodor M, Lenkei $Z$ and Heidland A. Atrial natriuretic factor in the subfornical organ and the organum vasculosum laminae terminalis. Prog Brain Res 1992; 91:251-259.

21) Quirion R, Dalpe M, De Lean A, Gutkowska J, Cantin M and Genest J. Atrial natriuretic factor (ANF) binding sites in brain and related structures. Peptides 1984; 5:1167-1172.

22) Salvaterra PM, Gurd JM and Mahler HR. Interactions of the nicotinic acetylcholine receptor from rat brain with lectins. $\mathrm{J}$ Neurochem 1977; 29:345-348.

23) Sirett NE, Mclean AS, Bray JJ and Hubbard JI. Distribution of angiotensin II receptors in rat brain. Brain Res 1977; 122:299312.

24) Spicer SS and Schulte BA. Diversity of cell glycoconjugates shown histochemically. A perspective. J Histochem Cytochem 1992; 40:1-38.

25) Sposito NM and Gross PM. Topography and morphometry of capillaries in the rat subfornical organ. J Comp Neurol 1987; 260:36-46.

26) Streit WJ, Schulte BA, Balentine JD and Spicer SS. Histochemical localization of galactose-containing glycoconjugates in sensory neurons and their processes in the central and 
peripheral nervous system of the rat. J Histochem Cytochem 1985; 33:1042-1052.

27) Stumpf WE, Bidmon H-J and Rühle H-J. Steroid hormones and circumventricular organs. Prog Brain Res 1992; 91:271-277.

28) Summy-Long JY and Severs WB. Macromolecular changes in the subfornical organ area after dehydration and renin. Am $\mathbf{J}$ Physiol 1979; 237:R26-38.
29) Toda N, Doi A, Jimbo A, Matsumoto I and Seno N. Interaction of sulfated glycosaminoglycans with lectins. J Biol Chem 1981; 256:5345-5349.

30) Weindl A, Bufler J, Winkler B, Arzberger $T$ and Hatt $H$. Neurotransmitters and receptors in the subfornical organ. Immunohistochemical and electrophysiological evidence. Prog Brain Res 1992; 91:261-269. 
Plate I
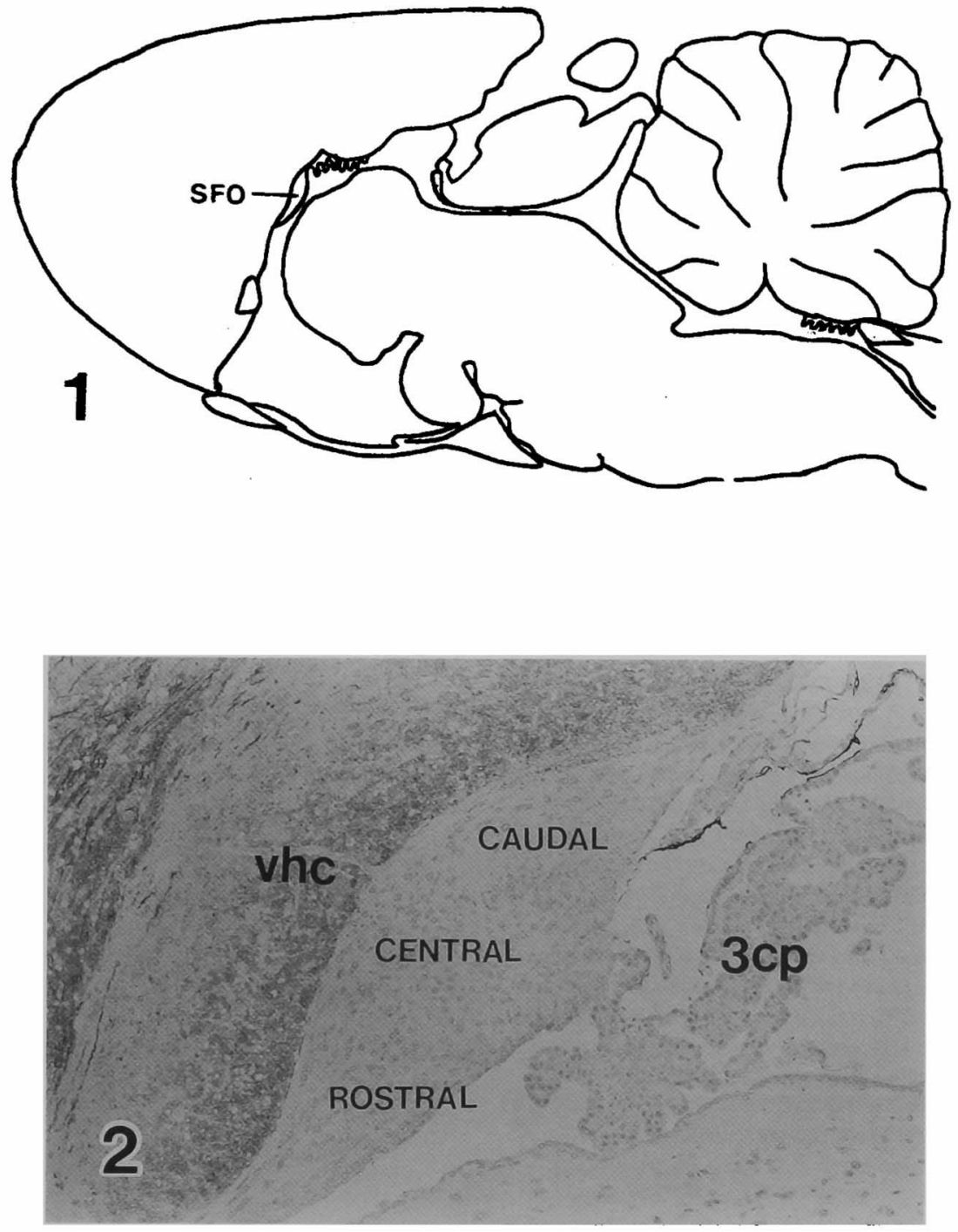

\section{Explanation of Figures}

\section{Plate I}

Fig. 1. A diagramatical illustration of a sagittal section through the region of the subfornical organ (SFO) in the rat brain. SFO: subfornical organ

Fig. 2. A mid-sagittal section indicating the three regions in the rat subfornical organ (SFO). $3 \mathrm{cp}$, choroid plexus of the third ventricle; vhc, ventral hippocampal commissure. UEA-1 stained. ( $\times 90)$ 


\section{Plate II}

Figs. 3-14. Light microscopic localization of lectin binding sites in the rat SFO, Sagittally sectioned.
Fig. 3 Con A $(\times 200)$
Fig. 5 LCA $(\times 200)$
Fig. 7 RCA-1 $(\times 200)$
Fig. 4 ePHA $(\times 200)$
Fig. 6 WGA $(\times 200)$
Fig. 9 PNA $(\times 200)$
Fig. 8 RCA-1 $(\times 400)$
Fig. 11 LFA $(\times 200)$
Fig. 10 PNA $(\times 400)$
Fig. 13 UEA-1 $(\times 200)$
Fig. 12 DBA $(\times 200)$

Fig. 14 PNA in the presence of 0.1 M D-galactose (Control) $(\times 200)$ 
Plate II
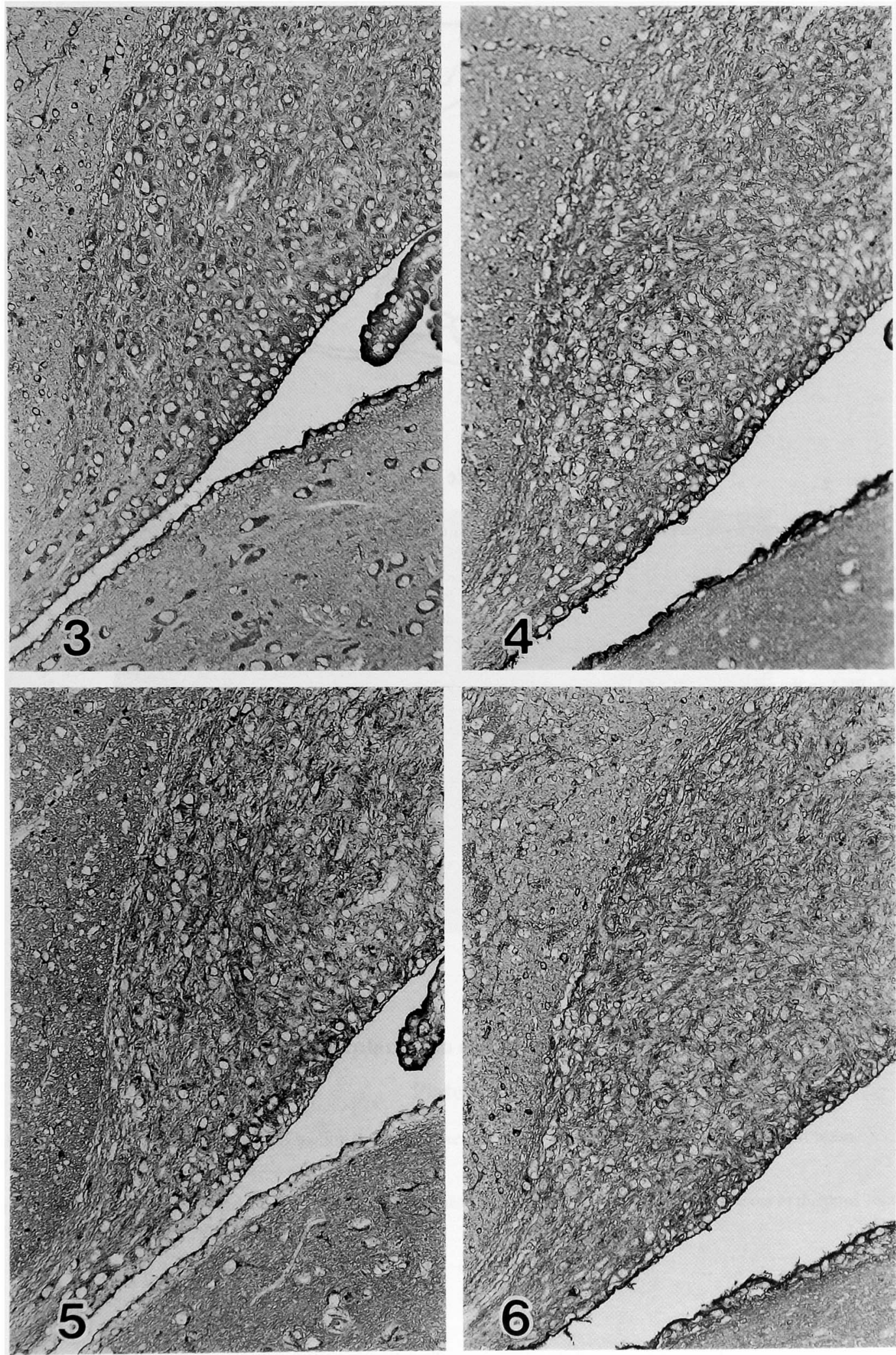

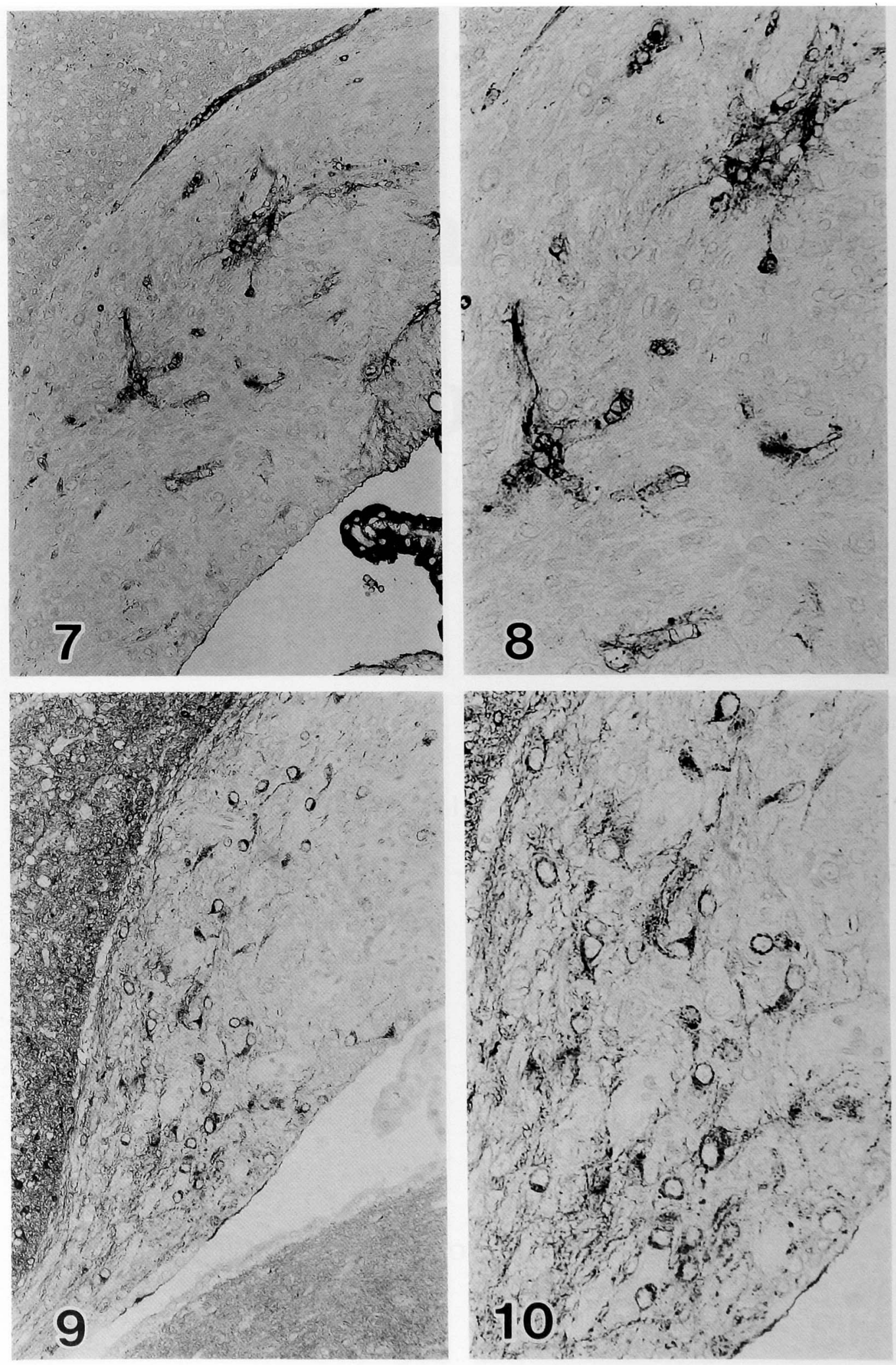

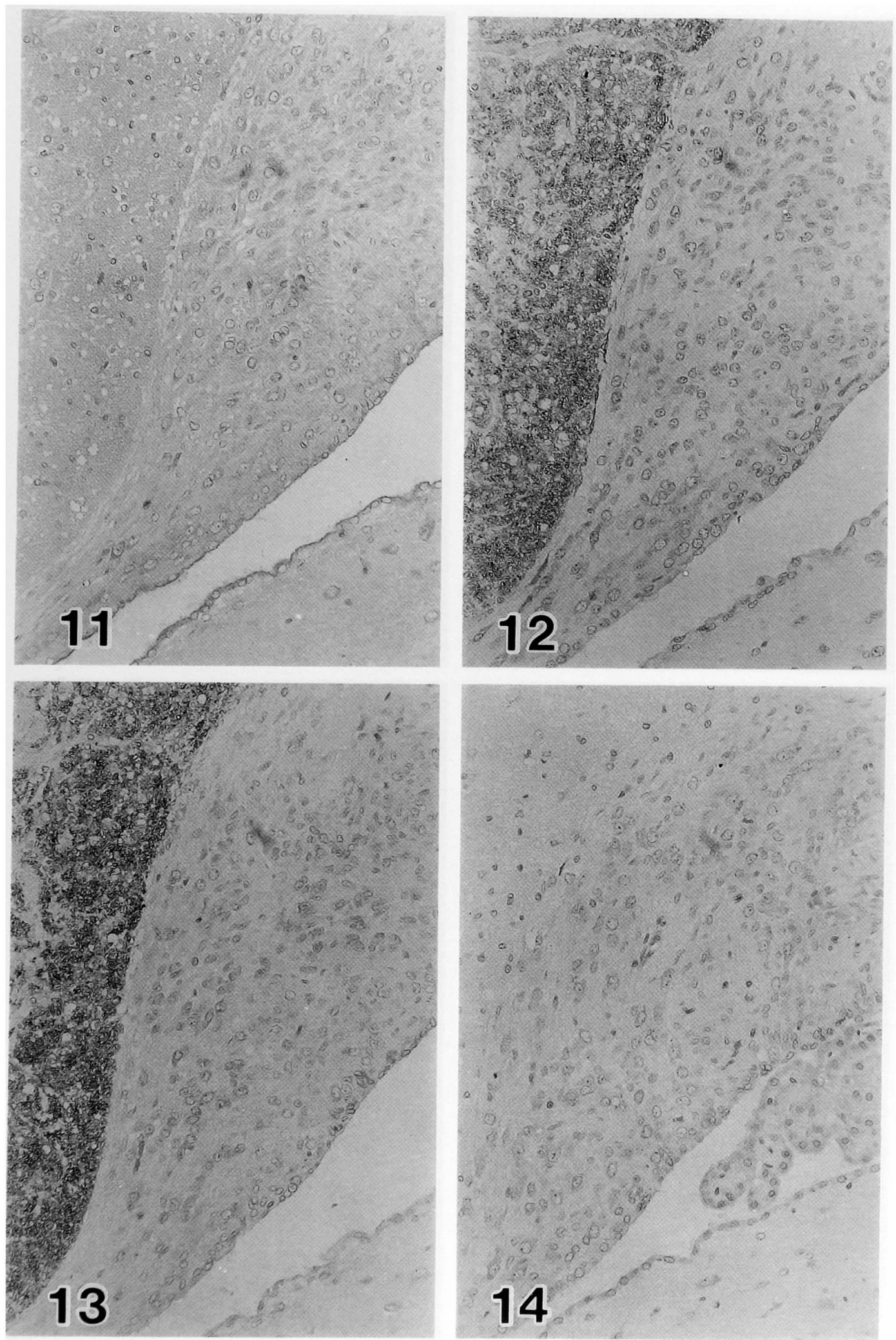